\title{
A Case of Sebaceous Trichofolliculoma on the Right Cheek
}

\author{
Sang Yeob Seong, Bo Gyung Kim, Hyung Rok Lee and Hyun Jun Hong \\ Department of Otorhinolaryngology, Yonsei University College of Medicine, Seoul, Korea
}

\section{우측 안면부에 발생한 피지털모낭종 1 예}

성상엽 · 김보경 · 이형록 · 홍현준

연세대학교 의과대학 이비인후과학교실

Received March 16, 2011

Revised May 12, 2011

Accepted May 18, 2011

Address for correspondence

Hyun Jun Hong, MD

Department of Otorhinolaryngology,

Yonsei University

College of Medicine,

211 Eonju-ro, Gangnam-gu,

Seoul 135-720, Korea

Tel $+82-2-2019-3460$

Fax $+82-2-3463-4750$

E-mail hjhong@yuhs.ac
Sebaceous trichofolliculoma is a rare benign tumor and represents a variant of trichofolliculoma. Up to now, only 5 cases of sebaceous trichofolliculoma were reported in Korea. It generally presents as a centrally depressed solitary tumor and occurs in areas rich in sebaceous lobules. Microscopically, it shows cystic cavities with or without keratin-filled portion and sebaceous lobules. The lobules are connected to the cystic wall. We report a case of infected sebaceous trichofolliculoma on the right cheek accompanied by a unilateral microtia in a 16year-old man. The patient was treated with oral antibiotics and surgical excision. By summarizing 12 past cases, 6 Korean and 7 international, we have put together clinical features of Sebaceous trichofolliculoma.

Korean J Otorhinolaryngol-Head Neck Surg 2011;54:650-3

\section{서 론}

피지털모낭종(sebaceous trichofolliculoma)은 1980년 Plewig ${ }^{1)}$ 가 처음 보고한 모낭종(trichofolliculoma)의 변종으 로서 국내에는 5예 ${ }^{2-6}$ 만 보고된 매우 드물게 발생하는 양성의 안면부 피부종양이다. 임상적으로 현재까지 보고된 문헌에 의 하면 돌출된 모발을 포함한 중심부 함몰이 있는 단발성 결절 로 존재하며 주로 피지샘이 풍부한 코에 발생하는 것으로 알 려져 있다. 병리조직학적 소견으론 방사상으로 위치한 많은 모피지낭들이 중층편평상피로 둘러싸인 낭포성 공간에 연결 되어 있는 소견을 보인다.7) 저자들은 우측 소이증과 외이도 협 착증 과거력을 가진 16 세 남자의 오른쪽 뺨에 모발이 없이 단 발성으로 발생하여 염증 및 농양을 동반한 피지털모낭종 1예 를 경험하여 보고하는 바이다.

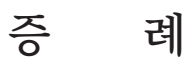

16 세 남자가 1 개월 전부터 시작된 우측 구강점막의 이물감을
주소로 내원하였다. 우측의 편측 소이증(microtia)(Fig. 1A) 으로 2차례 수술 받은 과거력이 있었으며, 특이 가족력은 없 었다. 신체검사에서 우측에 압통 없이 약간 융기된 $1 \mathrm{~cm}$ 정도 크기의 구강점막 소견만이 관찰되었으나, 1 주 후 외래에 내원 시 우측 뺨에 누공(fistula)이 관찰되었다(Fig. 1B). 당시 시행 한 경부전산화단층촬영에서는 우측 깨물근(masseter muscle) 앞쪽으로 균일하지 않은 음영(heterogeneous)의 약 $2 \mathrm{~cm}$ 크기의 비교적 경계가 뚜렷한 원형의 종괴가 관찰되었다(Fig. 2). 환자와 보호자와 상담 후에 치료적 목적을 위해 절제술을 계획하였다. 수술 예정일을 앞두고 환자는 누공 주위로 압통 과 발적 및 농이 배출되는 소견(Fig. 1C)이 관찰되어 외래에서 부분마취 하에 절개 및 배농하였으며, 항생제를 복용하면서 2주간 배액관을 유치하였다. 이후 염증 소견 호전되었으며, 피 부표면에 누공이 의심되었기에 이후 우측 뺨과 구강 양측을 절개하여 절제술을 시행하였다. 수술 소견으론 익돌판(pterygoid plate) 주변까지 누공로가 진행하였으나 구강점막으로의 연결은 없었다. 절개를 양측에서 시행하였던 것은 두 가지 장 점 때문이었다. 첫째, 종괴를 구강 내에서 제거하는 방법을 선 
택함으로써 피부 상처를 최소화하였고, 그럼으로써 뺨에는 누공이 의심되는 표면의 개구부(opening) 크기만큼만 절개할 수 있었다. 둘째, 얼굴신경(facial nerve)의 손상을 피할 수 있 었다. 종괴 크기가 작지 않았기 때문에 얼굴 피부에 크게 절 개를 하여 박리할 경우 얼굴신경의 볼가지와 하악가지(buccal and marginal branch of facial nerve)의 손상 가능성이 있 다. 따라서 협부 점막에 절개를 하고 안면신경이 주행하는 면 (plane)보다 깊은 면(deep plane)에서 종괴를 박리함으로써 안 면신경을 안전하게 보존할 수 있었다. 환자는 수술 후 출혈, 혈 종, 부종 및 안면신경마비 등의 합병증 없이 수술 후 5일째 퇴 원하였다.

술 후 병리 조직검사에서 진피하부에 경계가 명확한 불규 칙한 모양의 낭포성 공간이 중층편평상피(stratified squamous epithelium)로 둘러 싸여 있었으며 염증세포의 침윤은 없이 그 주위에 잘 발달된 피지샘들(sebaceous lobules)이 방 사상으로 배열되어 있는 소견이 관찰되어 피지털모낭종(sebaceous trichofolliculoma)으로 진단되었다(Fig. 3). 현재 수술 후 재발이나 상처 부위의 합병증 없이 외래 경과 관찰 중이다.

\section{고 찰}

피지털모낭종은 1980년 Plewig'에 의해 처음 보고된 드문 과오종성 양성 종양이다. Plewig ${ }^{1)}$ 은 코에 단발성의 중심부가 함몰되어 소수의 돌출된 모발을 가지고 있는 4 12 mm 크기 의 피부색 병변 3예를 보고하였다. 병리조직학적 소견으로 모 낭 및 다수의 피지샘 소엽들이 비교적 큰 중심부의 공동에 연
결되어 있는 양상을 나타내므로 모낭종(trichofolliculoma) 의 한 변형으로 생각하여 피지털모낭종이라 명명하였다.

현재까지 보고된 증례에 의하면 병변은 성인에서 호발하며 피지샘이 풍부한 코 부위에 단발성으로 발생한 경우가 대부 분이었으나 드물게 음낭과 음경에 다수의 병변을 보인 예도 보고된 바 있다. ${ }^{8)}$ 국내에 보고된 증례는 현재까지 총 5예 ${ }^{2-6)}$ 가 보고되었다. 증례는 1 예2)를 제외하고는 모두 여자 환자였으며, 1 예 ${ }^{3)}$ 를 제외하고 모두 성인 연령에서 발생하였고, 역시 1 예 ${ }^{4)}$ 외에는 Plewig ${ }^{1)}$ 의 증례와 같이 병변 중심부의 함몰이나 돌출 된 모발은 존재하지 않았다. 1 예 ${ }^{3}$ 는 7 세 여아의 아래눈꺼풀에 단발성의 구진(papule)으로 발생하였고, 다른 1 예 ${ }^{4}$ 는 두피에 단발성의 다리모양(pedunculated) 결절로 발생하였으며, 2예 ${ }^{5,6)}$

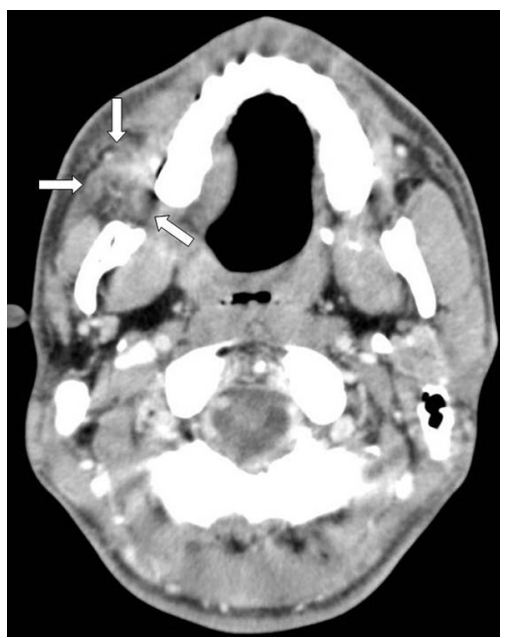

Fig. 2. Axial post-contrast enhanced CT: $2 \times 2 \mathrm{~cm}$ sized heterogenous, round mass in front of right masseter muscle (arrow).
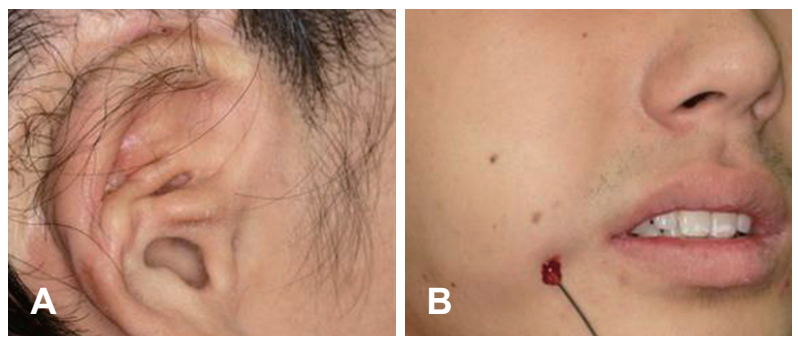

Fig. 1. Photograph shows right external ear that has undergone an operation for the microtia many years ago (A). Photograph shows non-tender, soft mass on the right cheek area with suspected fistula tract $(B)$. The infectious status on the right cheek area mass $(\mathrm{C})$.
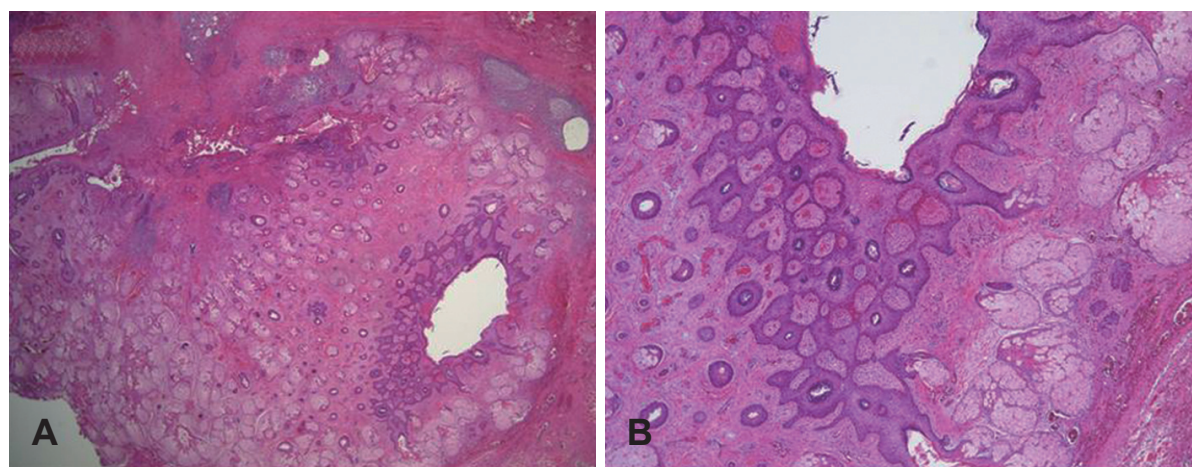

Fig. 3. Histopathologic findings. Large cystic cavity lined by squamous epithelium and radially arranged sebaceous follicles ( $\mathrm{H} \& \mathrm{E}$ stain, $\times 20)(A)$. Dilated cystic cavity is lined by squamous stratified epithelium. Well-differentiated sebaceous lobules are placed around the cystic cavity $(\mathrm{H} \& \mathrm{E}$ stain, $\times 40)(\mathrm{B})$. 
Table 1. Summary of reported cases of sebaceous trichofolliculoma in world literatures

\begin{tabular}{|c|c|c|c|c|c|c|}
\hline $\begin{array}{c}\text { Case } \\
\text { report } \\
\end{array}$ & $\begin{array}{l}\text { Gender/ } \\
\text { Age }\end{array}$ & Location & Clinical features & $\begin{array}{l}\text { Associated } \\
\text { symptom }\end{array}$ & Treatment & Course \\
\hline \multirow[t]{3}{*}{ Plewig ${ }^{1)}$} & $M / 21$ & Nose & $\begin{array}{l}\text { Solitary skin-colored, } 1.5 \mathrm{~mm} \text { deep } \\
\text { central depressed papule }\end{array}$ & Absent & Excision & $\begin{array}{l}\text { No recurrence during } \\
7 \text { years after excision }\end{array}$ \\
\hline & $M / 36$ & Nose & & Absent & Excision & $\begin{array}{l}\text { No recurrence during } \\
6 \text { years after excision }\end{array}$ \\
\hline & $M / 51$ & Nose & & Absent & Excision & $\begin{array}{l}\text { No recurrence during } \\
6 \text { years after excision }\end{array}$ \\
\hline Mohri et al. ${ }^{10)}$ & $F / 43$ & Nose & $\begin{array}{l}\text { Solitary, skin-colored, central } \\
\text { opening-like nodule }\end{array}$ & Absent & Excision & Biopsy only \\
\hline $\begin{array}{l}\text { Hashimoto } \\
\text { et al. }{ }^{11)}\end{array}$ & $M / 48$ & Nose & $\begin{array}{l}\text { Solitary, } 5 \times 5 \mathrm{~mm} \text { sized, skin- } \\
\text { colored nodule }\end{array}$ & Absent & Excision & $\begin{array}{l}\text { No recurrence during } \\
6 \text { months after excision }\end{array}$ \\
\hline Ueki et al. ${ }^{12)}$ & $\mathrm{F} / 57$ & Nose & $\begin{array}{l}\text { Solitary, } 1 \mathrm{~cm} \text { sized red } \\
\text { pedunculated nodule }\end{array}$ & Absent & Excision & $\begin{array}{l}\text { No recurrence during } \\
1 \text { year after excision }\end{array}$ \\
\hline $\begin{array}{l}\text { Nomura } \\
\text { et al. }{ }^{8)}\end{array}$ & $M / 22$ & Penis & $\begin{array}{l}\text { Multilple, skin-colored, yellowish } \\
\text { central opening nodules }\end{array}$ & Absent & Excision & No recurrence* \\
\hline Park et al..$^{3)}$ & $\mathrm{F} / 7$ & $\begin{array}{l}\text { Lt. lower } \\
\text { eyelid }\end{array}$ & $\begin{array}{l}\text { Solitary skin-colored } 0.7 \times 0.3 \times \\
0.8 \mathrm{~cm} \text { sized papule }\end{array}$ & Absent & Excision & No recurrence* \\
\hline Kim et al. ${ }^{4)}$ & $F / 21$ & Scalp & $\begin{array}{l}\text { Solitary whitish-gray colored } \\
1.3 \times 0.7 \times 0.7 \mathrm{~cm} \text { sized centrally } \\
\text { depressed pedunculated nodule }\end{array}$ & Absent & Excision & No recurrence* \\
\hline Ko et al. ${ }^{5)}$ & $F / 27$ & Nose & $\begin{array}{l}6 \text { light brown colored pin-head } \\
\text { sized papules }\end{array}$ & Absent & $\begin{array}{l}\text { Only } 1 \text { lesion } \\
\text { was excised }\end{array}$ & $\begin{array}{l}\text { No recurrence during } \\
11 \text { months after excision }\end{array}$ \\
\hline Ryu et al. $\left.{ }^{6}\right)$ & $F / 86$ & Nose & $\begin{array}{l}\text { Solitary flesh-colored dome- } \\
\text { shaped papule }\end{array}$ & Absent & Excision & No recurrence* \\
\hline Hong et al. ${ }^{2}$ & $M / 64$ & $\begin{array}{l}\text { Rt. Zygoma } \\
\text { area }\end{array}$ & $\begin{array}{l}\text { Solitary } 1.0 \mathrm{~cm} \text { sized flesh-colored } \\
\text { dome-shaped nodule }\end{array}$ & Absent & Excision & $\begin{array}{l}\text { No recurrence during } \\
12 \text { months after excision }\end{array}$ \\
\hline $\begin{array}{l}\text { Present case } \\
(2011)\end{array}$ & $M / 16$ & Rt. cheek & $\begin{array}{l}\text { Solitary } 3.0 \times 3.0 \mathrm{~cm} \text { sized flesh- } \\
\text { colored nodule, with skin opening }\end{array}$ & $\begin{array}{l}\text { Inflammation } \\
\text { sign }\end{array}$ & Excision & $\begin{array}{l}\text { No recurrence during } \\
6 \text { months }\end{array}$ \\
\hline
\end{tabular}

*the follow up period was not described in detail. Rt: right, Lt: left

는 코에 발생하였는데 각각 다발성ㅎㄱㄱㅘ 단발성()의 구진 형태 로 발생하였다. 1 예 $^{2)}$ 는 남자 환자의 광대뼈 피부에 단발성의 결절로 발생하였다.

현재까지 국내외에 보고된 문헌을 종합해보면, 해외에서는 거의 코에 발생하였으나, 국내에서는 코 외에 두경부 피부에 발생한 경우가 더 많았다. 형태학적으로도 해외에서는 중심 부 함몰 및 누공과 같은 개구부(fistula-like opening)를 가진 증례가 5 예 ${ }^{1,8,10}$ 로 대부분이었으나, 국내에서는 본 증례를 포 함하여도 그와 같은 소견은 2 예 ${ }^{4}$ 에서만 관찰되어 대조를 보 였다. 하지만 이와 같은 국내외 결과를 종합하였을 때는 피지 털모낭종에 있어서 남녀성비나, 중심부함몰 유무가 거의 $1: 1$ 로 차이를 보이지 않았다. 또한 병변은 주로 코에 많이 발생하 였으나, 두피, 눈꺼풀 주위, 뺨, 음경 등 피지선이 있는 곳이면 어디에서나 발생 가능한 병변으로 생각된다. 평균연령은 국내 외 모두 30대 후반으로 평균 37.9세였으나 7세의 소아부터 86 세의 노인까지 광범위하게 분포하였다. 하지만 각각의 증례보 고를 살펴보면 병변은 대부분 언제 발생했는지 환자가 모를 정도여서 병변의 생성시기는 소아 때부터일 것으로 추정되나, 증상 자체가 거의 없는 병변이기 때문에 진단되는 시기가 늦 어진 것으로 보인다(Table 1).

병리조직학적 소견으로 종양은 진피 내에 다소 크고 불규
칙한 모양의 낭포성 공간이 위치하며 내부는 각질로 채워져 있고 공간의 벽은 주위로 가지 모양으로 뻗어있는 중층편평 상피로 구성된다. 그 벽에 많은 모피지낭들이 방사상으로 배 열되어 중심부의 낭포성 공간에 연결되어 있는 것이 특징적인 소견이다. ${ }^{79)}$ 본 증례에서는 진피 하부의 낭포성 공간 내에 각 질 성분은 거의 없었으나 잘 발달된 피지샘들이 낭포성 공간 주위에 방사상으로 배열되어 있는 소견으로 보여 피지털모낭 종의 특징적인 소견과 일치하였다.

감별질환은 피지샘증식증(sebaceous hyperplasia), 유피낭 종(dermoid cyst), 정중 코 유피낭 샛길(median nasal dermoid fistula), 모낭피지샘 낭성 과오종(folliculosebaceous cystic harmatoma) 등이 있다. ${ }^{9)}$ 특히 모낭피지샘 낭성 과오종은 조 직학적으로 감별이 필수적이다. 즉 피지털모낭종과 매우 유사 한 소견을 보이는데, 조직학적으로 진피 내에 표피나 모낭성 누두부의 상피와 유사한 편평상피로 이루어진 낭성 구조물이 있고, 내부에는 각질 파편들과 피지샘 분비물이 차 있으며 그 주위로 다수의 피지샘 소엽들이 피지샘관을 통해 연결되어 방사상으로 둘러싸는 유사한 소견을 보인다. 하지만 이러한 조직 주위로 치밀한 판상 배열을 보이는 교원질의 섬유증식 증(fibroplasia)이 동반되는데, 섬유상피단위(fibroepithelial unit) 주위로 교원섬유, 탄력섬유, 지방 및 혈관조직 등을 포함 
한 간엽조직의 증식이 관찰되며 이들 사이에 열(cleft)과 같은 공간이 관찰되는 것이 특징이다. 피지털모낭종에서는 이러한 특징적인 기질의 변화가 관찰되지 않으므로 감별이 가능하다."

본 환자의 과거력에 선천적인 소이증이 동반되어 있었으나, 현재까지 피지털모낭종과 관련된 선천성 기형은 보고된 바 없 다. 일반적인 치료의 원칙은 외과적 절제술로 권고되고 있으며 재발은 보고되지 않았다. 본 증례에서도 단순절제술로 완전 히 제거한 후 현재까지 재발은 없었다.

지금까지 보고된 피지털모낭종의 경우 모두 증상이 없었 고, 미용적인 이유로 치료를 받았으나, 본 증례의 환자는 입안 에 이물감이 느껴질 정도의 불편감이 있었고, 병변의 중심부 함몰부위를 통해 염증이 파급되어 농양까지 진행되어 지금까 지 보고된 예들과는 다른 진행을 보였다. 이러한 염증 및 감염 은 구조상으로 볼 때 함몰 부위가 있는 병변에 더 잘 생길 것 으로 추정되나 더 많은 증례의 보고 및 고찰이 필요할 것으로 생각된다. 또한 병변이 크고 안쪽으로 깊게 위치해 있었으며 안면신경이 주위로 주행하여, 상처의 최소화와 함께 안면신경 의 보존이 중요하였다. 피지털모낭종이 안면부에 잘 생김을 감 안했을 때 구강내 접근법은 본 증례와 같이 종괴가 큰 경우 미용적인 면과 함께 안면신경의 보존이라는 두 가지 이점을 가지는 좋은 방법이라고 생각된다.

이와 같이 저자들은 염증 및 농양을 동반한 오른쪽 뺨에
발생한 피지털모낭종 1 예를 경험하고 드문 예라 생각하여 문 헌고찰과 함께 보고한다.

\section{REFERENCES}

1) Plewig G. Sebaceous trichofolliculoma. J Cutan Pathol 1980;7(6): 394-403.

2) Hong JS, Rhee JH, Lee JS, Cho YS, Yun SK, Kim HU. A case of sebaceous trichofolliculoma. Korean J Dermatol 2009;47(7):835-7.

3) Park HC, Lee HB, Oh SJ. A case of sebaceous trichofolliculoma in lower eyelid margin. J Korean Opthalmol Soc 1994;35(10):1291-4.

4) Kim J, Lee SB, Kang SJ, Chung SI, Kim SM. Sebaceous trichofolliculoma. Korean J Pathol 1995;29(6):794-6.

5) Ko GB, Hong SS, Chon TH, Yun SK, Kim HY. A case of sebaceous trichofolliculoma. Korean J Dermatol 2001;39(9):1063-5.

6) Ryu HJ, Song HJ, Oh C. A case of sebaceous trichofolliculoma. Korean J Dermatol 2003;41(12):1662-3.

7) Klein W, Chan E, Seykora JT. Tumors of the epidermal appendages. In: Elder D, Elenitsas R, Haworsky C, Johnson B Jr, Murphy G, editors. Lever's histopathology of the skin. $9^{\text {th }}$ ed. Philadelphia: Lippincott Williams \& Wilkins;2005. p.871.

8) Nomura M, Hata S. Sebaceous trichofolliculoma on scrotum and penis. Dermatologica 1990;181(1):68-70.

9) Mckee PH, Calonje E, Granter SR. Pathology of the skin with clinical correlations. $3^{\text {rd }}$ ed. London, England: Elsevier Mosby;2005. p. $1542-6$.

10) Mohri S. Pilar acanthoma: a combination of inverted follicular keratosis and sebaceous trichofolliculoma. J Dermatol 1981;8(6):479-81.

11) Hashimoto $Y$, Ishida $A$, Matsuo $S$, Iizuka $H$. A case of sebaceous trichofolliculoma. Rinsho Hifuka 1988;42:163-7.

12) Ueki $T$, Kinebuchi $S$, Tada E, Takahashi N, Kumakiri M. Sebaceous trichofolliculoma. Rinsho Derma (Tokyo) 1988;30:347-9. 